International Journal of Virology Studies \& Research (IJVSR)

ISSN:2330-0027

\title{
Novel Approaches to the Prevention and Treatment of Rabies
}

\author{
Gnanadurai CW ${ }^{1}$, Huang CT ${ }^{1}$, Kumar $\mathrm{D}^{1}$, Zhen F. Fu ${ }^{1,2^{*}}$ \\ Review Article \\ ${ }^{1}$ Department of Pathology, College of Veterinary Medicine, University of Georgia Athens, USA. \\ ${ }^{2}$ State-key Laboratory of Agricultural Microbiology, College of Veterinary Medicine, Huazhong Agricultural University, China.
}

\begin{abstract}
Rabies is a highly lethal disease caused by the neurotropic rabies virus (RABV), and it remains an important public health problem globally. Effective vaccines have been developed for pre- and post-exposure prophylaxis (PEP). PEP is only effective if it is initiated promptly after recognizing exposure. Once neurological symptoms develop, however, it is widely accepted that there is no effective treatment available. Recent studies indicate that the presence of RABV-specific immunity (i.e. Virus neutralizing antibodies, VNA) and the transient enhancement of the BBB permeability are absolutely required for effective virus clearance from the CNS. In principle, it has been shown in mice using various live-attenuated RABVs or recombinant RABVs expressing three copies of the $G$ or expressing chemokine/cytokines, which can induce high levels of VNA in the serum and also capable of transiently enhancing the BBB permeability that it is possible to clear the virus from CNS. Also, it has been demonstrated that, intravenous administration of VNA together with MCP-1 (shown to transiently open up BBB) can clear RABV from the CNS in both immunocompetent and immunocompromised mice, as late as 5 days after lethal challenge. Novel therapeutic approaches aimed at allowing the peripheral VNA to cross the BBB by administration of the VNA in combination with biological or chemical agents that can transiently open up the BBB would be useful to establish an effective therapy for rabies in humans. In this review, we focus on the some of the approaches that can be used to meet the challenges in the field of rabies treatment.
\end{abstract}

Keywords: Rabies Virus; Pathogenesis; Post-Exposure Prophylaxis; Virus Neutralizing Antibodies; Blood-Brain Barrier; Therapy; Treatment.

\author{
*Corresponding Author: \\ Zhen F. Fu, \\ Department of Pathology, College of Veterinary Medicine, University of \\ Georgia, 501 D.W. Brooks Drive, Athens, GA 30602, USA. \\ Tel: 706-542-7021 \\ Fax: 706-542-5828 \\ E-mail: zhenfu@uga.edu
}

Received: January 22, 2015

Accepted: April 06, 2015

Published: April 07, 2015

Citation: Gnanadurai CW, Huang CT, Kumar D, Zhen F. Fu (2015) Novel Approaches to the Prevention and Treatment of Rabies. Int J Virol Stud Res, 3(1), 8-16. doi: http://dx.doi.org/10.19070/2330-0027-150002

Copyright: Zhen $\mathbf{F} . \mathbf{F u}^{\circ}$ 2015. This is an open-access article distributed under the terms of the Creative Commons Attribution License, which permits unrestricted use, distribution and reproduction in any medium, provided the original author and source are credited.

\section{Introduction}

Rabies (Latin, "madness") is a highly lethal zoonotic disease caused by a neurotropic rabies virus (RABV) of the Lyssavirus genus, in the family of Rhabdoviridae, order Mononegavirales. These are bullet or rod-shaped enveloped viruses with a negativesense, single-stranded RNA genome [1]. RABV infects a wide range of hosts, including dogs, cats, raccoons, skunks, foxes, coyotes, bats, and human beings [2]. RABV is usually transmitted to humans through a bite from domesticated or wild animals. It invades the central nervous system (CNS) which leads to acute encephalitis and death $[2,3]$. It has been estimated that about 70,000 people die from rabies each year, mostly in Africa and Asia [4]. Effective vaccines have been developed for pre-and postexposure prophylaxis (PEP). Timely administration of PEP can prevent the development of rabies, when individuals are exposed to the virus. The PEP includes through cleansing of the wound, administration of vaccines and equine or human rabies immune globulins (ERIG or HRIG) [5, 6]. However, the PEP is ineffective once neurological signs have appeared. Yet, there are a few reports on human rabies survivors, but no effective/established therapy is available till date. Improvements in the treatment of rabies are often translated from key studies of its pathogenesis in animal models. The purpose of this article is to review the current literature and to highlight the novel approaches attempted to the prevention and treatment of rabies using animal models.

\section{Rabies: Virus and Disease}

\section{Molecular characteristics of RABV and epidemiology of ra- bies}

RABV has a non-segmented and negative-strand RNA genome and its genetic information is organized in the form of a helical ribonucleoprotein complex (RNP), in which the linear RNA is tightly associated with the viral nucleoprotein. The genome of RABV encodes for only five proteins in the order: nucleoprotein 
$(\mathrm{N})$, phosphoprotein $(\mathrm{P})$, matrix protein $(\mathrm{M})$, glycoprotein $(\mathrm{G})$, and the large protein $(\mathrm{L}$, also termed RNA-dependent RNA polymerase, RdRp) [1]. The $\mathrm{N}$ plays a critical role in viral transcription and replication [7]. The $\mathrm{G}$ forms approximately 400 trimeric spikes, which are tightly arranged on the surface of the virions [8]. The $\mathrm{G}$ is a major determinant for RABV neuropathogenicity by binding specific receptor(s), entering the nervous system through the endosomal transport pathway [9] via a low-pH-induced membrane fusion process [10]. The N-L-P polymerase complex starts transcription with the production of a short RNA molecule, the leader RNA, that is neither capped nor polyadenylated. Subsequently, mRNAs are produced for N, P, M, G and L. The switch between transcription and replication of genomic RNAs are controlled by the level of $\mathrm{N}$ protein [11]. All transcription and replication events take place in the cytoplasm inside a specialized 'virus factory', the Negri body [12].

According to the World Health Organization (WHO), approximately 30,000 people die of rabies each year in Asia [13]. It is estimated that more than 3 billion people are exposed to dog rabies in Asia. One Asian dies every 15 minutes among them 15\% are likely to be children under 15 years of age. In India, about 15 million people are bitten by dogs every year, it has been reported that annually $25,000-30,000$ deaths occur due to rabies, and around 2,500,000 people undergo PEP. Nepal has one of the highest reported per capita rates of human rabies deaths in the world [14]. Rabies is an important public health problem in Bangladesh, where nearly 100,000 people were bitten by dogs in 2009 and 3,000 died of rabies [13]. In Pakistan, it is estimated about 2,500 deaths occur due to rabies and around 70,000 people undergo PEP treatment [13]. Rabies causes at least 24,000 deaths per year in Africa and the highest death rates are reported in poor rural communities and children [13]. Human rabies has been disappearing from many European and American countries, mainly due to the enforced policy of pet vaccination programs.

\section{Animal reservoirs and human exposure}

Although all mammals are susceptible to RABV, only a few species are important as reservoirs for the disease. Dogs remain the most important reservoirs for rabies in the developing countries of Asia and Africa [15]. In the developed nations, dog rabies has been eliminated or controlled through mass vaccination during the past 70 years [16]. However, wildlife rabies becomes a major concern. In North America, rabies is endemic in raccoons, foxes, coyotes and skunks [16] while fox rabies is endemic in Europe [17]. Wolves, jackals, and other wild animal species have also been reported as reservoirs in other regions $[18,19]$. Bats are probably the ultimate reservoirs for $\mathrm{RABV}$ [16, 20-22]. In the Americas, a number of bat species carry distinct RABV strains [23], whereas in Europe and Australia bats carry rabies-related lyssaviruses [15].

\section{Rabies vaccines and PEP}

\section{Current human rabies vaccines and PEP}

Successful vaccines have been developed for PEP by Louis Pasteur in 1885 . The initial vaccine was prepared from the rabid rabbit spinal cord (nerve tissue); subsequently, the vaccine preparation progressed from nerve tissues to cell cultured RABV. The current PEP consists of through cleansing of the wound and timely administration of vaccine and anti-rabies immunoglobulin (RIG) [5, 24]. PEP can prevent the development of rabies in exposed individuals, only when administered immediately after exposure [25]. The aim of administering rabies specific antibodies at the site of exposure is to immediately neutralize the virus and prevent the virus from entering the CNS [26]. Vaccination is then provided to induce the host immune system to combat the virus during the time period between exposure and the onset of clinical signs (incubation period). Current vaccines used for rabies prophylaxis are inactivated RABV, derived from primary cell cultures. Among the available rabies vaccines, WHO regards the human diploid cell vaccine (HDCV) as the gold standard [27]. The purified chick embryo cell vaccine (PCECV) is prepared from a fixed strain of FLURY LEP grown in primary cultures of chicken fibroblasts, which is used worldwide and shown to be equally effective and cheaper than HDCV [28]. Purified Vero cell vaccine (PVRV) is the most recent cell culture rabies vaccine, which is currently available in more than 100 countries in Europe, Asia, Africa and Latin America. It has been widely and routinely used in many countries for both pre- and post-exposure prophylaxis [29, 30]. Currently, equine or human rabies immune globulin (ERIG or HRIG) for PEP is prepared from pooled sera taken from hyper-immunized horses and humans, respectively. However, ERIG can cause serious adverse reactions while HRIG is expensive for patients, particularly in the developing countries. In addition, its availability is limited worldwide [31].

\section{Rabies vaccines in pets and wildlife animals}

Inactivated RABV vaccines are currently used for routine vaccination of pet animals like dogs and cats, however, multiple immunizations have to be carried out to provide sufficient immunity throughout the life of the animals [32]. Oral rabies vaccines (liveattenuated or live-recombinant vaccines) have been successfully developed for wildlife and two of them are commercially available $[33,34]$. Vaccinia virus expressing RABV G (VRG) is found to be an effective oral immunogen for raccoons and foxes under laboratory settings and in the field $[35,36]$. Although VRG is safe and effective in vaccinated animals, its exposure to humans can induce skin inflammation and systemic vaccine infections [37]. SAG-2, derived from an attenuated Street Alabama Dufferin (SAD) strain, has been successfully used in Europe for oral immunization of foxes $[38,39]$. SAG-2 has also been shown to be safe, immunogenic and effective in dogs in field trails [40]. However, the immunogenicity of SAG-2 is low and only low levels of VNA titers are detected in the immunized dogs [41].

\section{Rabies Pathogenesis}

Despite the long history of human rabies, its pathogenic process remains poorly understood. Most of what we know about the disease process is acquired from investigations conducted in experimental animal models. The overall outcome of an exposure to RABV depends in part upon the rabies genotype (different strains and mutants) or variant involved, its pathogenicity (apoptogenicity, neuroinvasiveness), the dose of virus inoculated (severity of exposure), the route as well as the host species and its susceptibility to the particular pathogen together with innate and adaptive immune responses of the host [42]. However, various studies in animal models indicate that the pathogenic wild-type/street RABV and the fixed (laboratory-adapted) RABV evidently behave differently in each step of their life cycle in the host. RABV $G$ is the only surface protein of the virion and capable of inducing virus neutralizing antibodies (VNA) [43]. The G protein plays an important role in rabies pathogenesis [44] by binding to neural 
receptor such as acetylcholine receptor [45] and neural cell adhesion molecules (NCAM) [46] contributing to the exclusive neurotropism and neuroinvasiveness of RABV [47]. Virus may enter muscles and replicate at the site of inoculation or enter directly into peripheral nerves without prior replication in non-neural tissues [48]. It is believed that once virus particles enter the peripheral nervous system and start to spread to the CNS, a fatal outcome of the disease is inevitable, though there are some reports of rabies survivors. RABV enters motor and/or sensory axons of peripheral nervous system and spreads to the CNS by retrograde fast axonal transport at a rate of approximately $50-200 \mathrm{~mm} /$ day [49]. The pathogenic RABV have evolved specific mechanisms to escape early immune system recognition in the periphery via limited replication, minimized $G$ expression [50, 51], suppression of interferon response, anti-apoptotic stimulation, and transportation through neurons only. On the other hand, fixed RABV induces extensive inflammation by activating innate immune responses [51-53], induces apoptosis [54], replicates to higher levels and express high levels of the $G$ protein [55]. However, the mechanism adopted by the fixed RABVs to elicit immune responses and the wild-type RABVs to evade immune system is still not entirely clear. It has been shown that the innate immune responses and inflammation in the CNS is associated with BBB permeability enhancement $[56,57]$ in mice infected with fixed RABV but not in those infected with street RABV $[53,57,58]$. Current understanding on the striking difference between pathogenic and nonpathogenic rabies biology is summarized in the Table 1.

\section{Rabies management and therapy}

Rabies is traditionally considered a uniformly fatal disease after onset of clinical manifestations [59, 60]. To this date, there is still no effective therapy for those who develop rabies encephalomyelitis. However, there is now increasing evidence that non-lethal infection can occur in experimental animals as well as in humans [61-66]. There are many rabies case reports, but only a few cases of treated patients have been published. Only a few patients with acute illness have been reported to survive [63, 67-71]. The literature documents five human rabies survivors prior to 2004 [63, 67-70]. However, all of them received rabies vaccine before the onset of the clinical symptoms, but none of them received HRIG. High levels of VNA were detected in both serum and CSF, but no
RABV or rabies antigen was detected. Though only one had a full recovery without any neurological complication and all the others had partial recoveries and one of them died within four years due to severe complications. It is assumed that the neurological complications may be due to post-vaccination encephalomyelitis, which have been reported as a side effect of neuronal tissue vaccines [72]. Though these five cases received vaccination before the onset of clinical signs, it does not alter the fact that the mortality rate of the disease is $100 \%$ once the critical stage of incubation period is reached without any treatment.

However, recently there are few reports on rabies recovery. A 15 -year-old girl started developing a series of neurological symptoms one month after a bat bite exposure [66]. VNAs were detected in both serum and CSF upon hospitalization, and subsequently increased over time. She was then treated with "Milwaukee Protocol" which includes induction of therapeutic coma and administration of combination of antiviral agents, and immunotherapies including rabies vaccination, rabies immune globulin, ribavirin, interferon- $\alpha$ and ketamine. After the treatment, she was discharged from the hospital with neurologic deficits [71]. The most recent case was a 15-year-old boy from Brazil, who was attacked by a hematophagous bat and developed symptoms a month later. Prior to onset of symptoms, he received four doses of rabies vaccine and then was treated with therapeutically induced coma and other therapies ("Milwaukee protocol"). However, the patient survived with severe neurological sequelae. Out of the 5 survivors, treated with "Milwaukee Protocol" three of them had anti-RABV antibodies in CSF prior to treatment. However, since then, there have been at least 20 cases in which the main component of "Milwaukee Protocol" have been used and fatal outcomes have resulted [73]. The mechanisms involved in the prevention of lethal rabies using Milwaukee Protocol is not completely understood thereby, it is regarded ineffective and considered scientifically irrational by some rabies experts in treating human rabies [73-77].

However, one of the major findings associated with non-lethal infections is that many of the survivors had VNA in the serum and / or CSF, and high level of total protein in the CSF, which are likely the key to their survivals $[64,65]$. Thus, a combination of therapy pertaining to the induction of CSF VNA should be considered for the effective clearance of rabies viruses from the CNS.

Table 1. Striking difference between pathogenic and non-pathogenic RABV biology.

\begin{tabular}{|c|c|c|c|}
\hline & $\begin{array}{c}\text { Non-pathogenic virus } \\
\text { (fixed/lab-adapted) }\end{array}$ & $\begin{array}{c}\text { Pathogenic virus (street/ } \\
\text { wild-type) }\end{array}$ & References \\
\hline Cellular Tropism & Not exclusively neuronal & Highly neuronal & $(47,114)$ \\
\hline $\begin{array}{c}\text { Glycoprotein } \\
\text { Expression Levels }\end{array}$ & High & Low & $(55,114)$ \\
\hline Replication (titer) & High & Low & -47 \\
\hline Apoptosis & High & Highly sensitive & $(114,115)$ \\
\hline Interferon sensitivity & Resistant & $\begin{array}{c}\text { Evades innate/adaptive } \\
\text { immunity }\end{array}$ & $(51,116,117)$ \\
\hline Immune System & $\begin{array}{c}\text { Activates innate/adaptive } \\
\text { immunity }\end{array}$ & $\begin{array}{c}\text { Little or } \\
\text { no change }\end{array}$ & $\begin{array}{c}(53,56-58,79, \\
81,92)\end{array}$ \\
\hline $\begin{array}{l}\text { Blood-brain-barrier } \\
\text { (BBB) permeability }\end{array}$ & Enhances & &
\end{tabular}




\section{Immune clearance of RABV from the CNS}

It has been thought that it is very difficult to clear RABV once it enters into the CNS $[59,78]$. This assumption began to change when it was demonstrated in rats that RABV can be cleared from the CNS by intravenous administration of VNA [25]. Also, it has been demonstrated in mice that clearance of RABV from the CNS requires the presence of RABV-specific immunity (i.e., VNA) in the CNS and enhancement of BBB permeability [79]. $\mathrm{BBB}$ is composed of tightly packed endothelial cells, astrocytes end-feet and pericytes which selectively exclude most bloodborne substances from entering the brain [80]. It has been shown by Roy et al., that the lethal SHBRV infection can be prevented by opening the BBB [58]. Failure to open the BBB to deliver immune effectors to CNS leads to lethal rabies [57, 81]. These studies indicate the importance of BBB permeability enhancement in RABV clearance from $\mathrm{CNS}$.

By using experimental autoimmune encephalomyelitis disease model

The presence of $\mathrm{BBB}$ presents a huge challenge for effective delivery of therapeutic agents to the CNS. Many potential drugs against neurological diseases, which are effective at the site of action, have failed, due to their inability to cross the BBB to reach the CNS [82]. Understanding the mechanism involved in triggering the BBB permeability changes in mice clearing RABV and mice developing the CNS inflammatory disease in experimental autoimmune encephalomyelitis (EAE) might provide insight into how the therapeutic agents can be delivered across the BBB without neuropathological complications [56]. EAE is an animal model of multiple sclerosis (MS). MS is a chronic autoimmune disease of the CNS characterized by the breakdown of BBB and accumulation of inflammatory infiltrates in the CNS [83, 84]. Many similarities exist between the MS and rabies in terms of CNS immune pathology i.e. inflammation and demyelination [85]. However, in EAE elevated BBB permeability is associated with the development of neurological disease but not during the clearance of attenuated RABV from the CNS tissues. Comparison of therapeutic immune clearance of RABV and CNS autoimmunity (EAE) indicates that BBB permeability changes can occur in the absence of neuropathology provided that cell invasion is restricted [56]. Also, it is known that the BBB permeability changes, collaboration of VNA and inflammation in the CNS plays a crucial role in the clearance of RABV from the CNS. Opening of BBB using EAE models can be exploited for the RABV clearance from the CNS by the safe passage of peripheral VNA and other immune effectors across the CNS [60].

\section{By using attenuated RABVs}

Laboratory-attenuated RABVs have been used for developing animal vaccines and for studying rabies immunology. Many of these attenuated RABVs can spread to the CNS from the peripheral site of inoculation but can be cleared by specific immune responses provided the immune effectors must cross the BBB. Studies by Hooper et al., [86] showed that mice lacking either B and T cells or $\mathrm{B}$ cells alone developed a progressive disease and succumbed to infection when infected with attenuated RABV (CVS-F3). However, mice lacking either CD8+ T cells, IFN receptors, or C3 and C4 complement components had no significant differences from normal mice in the development of disease. These studies confirm that rabies VNA is an absolute requirement for the clearance of an established RABV infection. Subsequently, it has been shown by Roy et al., [57] that the induction of innate and adaptive immunity are indistinguishable between mice infected with highly lethal SHRBV and mice infected with attenuated RABV (CVS-F3). Though, CVS-F3 and SHBRV could spread to the CNS tissues from peripheral sites of inoculation but only the attenuated RABV could be cleared from the CNS, whereas the SHBRV infected mice succumb to the disease. It is found that the specific deficit in the SHBRV-infected mice, is an inability to enhance BBB permeability and to deliver the immune effectors to the $\mathrm{CNS}$, indicating that the failure to open the $\mathrm{BBB}$ to deliver immune effectors to the CNS leads to the lethal outcome in mice [58].

\section{By using recombinant RABVs expressing three copies of the $\mathbf{G}$}

In the past, vaccine virus were attenuated and selected by conventional method of serial passaging in vivo and in vitro, but recent advancement in biotechnology allows us develop highly attenuated live recombinant RABV by manipulating its genome targeting specific genetic elements that accounts for pathogenicity and immunogenicity using reverse genetics approach [87]. Using the reverse genetic technology, it has been shown in a fixed RV strain SADB19, that the changes in the single amino acid in the glycoprotein gene at position 333Arg $\rightarrow$ Glu completely abolished the pathogenicity in immunocompetent mice after intracranial (i.c.) inoculation [88]. Furthermore, change at position at 194Asn $\rightarrow$ Ser mutation prevents the reversion to pathogenic phenotype [89]. Duplication or triplication of this mutant $G$ gene significantly enhanced the immunogenicity of the vaccine through higher $G$ protein expression [90] and also decreased the chances of reversion to pathogenic phenotype [91]. Though, TriGAS is shown to be more effective than conventional rabies vaccines in inducing RABV-specific immunity, as well as in promoting immune effector delivery to CNS tissues, but it is also shown to effectively protect mice as late as 4 days after infection with lethal dose of wild-type RABV [92]. Like the CVS-F3, TriGAS has been shown to enhance the BBB permeability and stimulate a robust immune response for effective clearance of RABV from the CNS [93]. Transcriptome analysis revealed that the host-pathogen responses are responsible for RABV clearance including rapid production of VNA and the induction of factors that promote the activity of immune effectors in the brain [93], thus TriGAS can also be used as a tool for rabies therapy.

\section{By using recombinant RABVs expressing immune stimulat- ing agents}

Studies from our laboratory indicate that recruitment and/or activation of DCs plays an important role in enhancing protective immunity against RABV infection [94-96]. Insertion of innate immunity genes like cytokine/chemokine into vaccine candidates has been reported to increase vaccine immunogenicity by recruitment and/ or activation of DCs and B cells [96-98]. It has been found that intracerebral administration of recombinant RABV expressing GM-CSF effectively protected mice as late as 5 days after infection with wild-type RABV [95]. Administration of this rRABV by peripheral routes was not as effective. Intracerebral injection of this rRABV not only resulted in the production of VNA, but also in the enhancement of BBB permeability. However, enhancement of the BBB permeability alone is not sufficient to protect mice from developing rabies since administration of a 
chemokine, MCP-1, enhanced the BBB permeability, but did not significantly increase the survival rate in mice infected with wt RABV, when compared to those infected with wt RABV without MCP-1 treatment [96]. On the other hand, immunization with an inactivated RABV preparation 5 days after infection with street RABV did not increase significantly the survival rate either despite the fact that VNA was produced in the periphery. Yet, administration of MCP-1 (which can transiently enhance the BBB permeability) in mice immunized with inactivated RABV significantly improved the survival rate in mice infected with street RABV [96]. Thus the combined effects of enhancement of BBB permeability and the production of VNA are required for clearance of RABV from the CNS and prevention of mice from developing rabies. Also, it has been considered that VNA produced in situ by the invading $\mathrm{B}$ cells at the CNS is important in clearing RABV from the CNS, rather than VNA produced in the periphery and then transported into the CNS [79].

\section{By intrathecal administration of RABV vaccines}

It has been shown by Baer et al., in early 1970s that the intrathecal administration of attenuated rabies vaccine in dogs, not only induced VNA in the CSF, but also prolonged the morbidity [99]. Recently, it has been shown that the intrathecal inoculation of rabies vaccines directly into the CSF of rabbits showing neuromuscular symptoms of rabies, led to the clearance of RABV from the CNS and their survival [100]. Thus, these studies provide evidence of RBAV clearance from CNS and possible therapy for rabies using intrathecal RABV immunization.

By administration of VNA and transient opening of BBB transiently using MCP-1

Although, the live-attenuated RABVs (described above) are capable of clearing rabies virus from the CNS and thus could be used as possible agent for rabies therapy, however it poses safety concerns for human use and investigation of alternative methods without safety concerns are needed. Recent studies, however, indicates that intravenous administration of VNA together with MCP-1 that can transiently enhance the BBB permeability modulating agent resulted in the clearance of $\mathrm{RABV}$ from the CNS and prevented the development of rabies when given 5 days post infection with wt RABV [101]. As shown in the Figure. 1, untreated, B-cell deficient or C57BL/6J (immunocompetent/ background) mice all died by $12-14$ dpi. However, $80 \%$ of the immunocompetent mice treated with serum containing VNA and MCP-1 survived. It is also observed that, only $25 \%$ of the B-cell deficient mice survived the lethal rabies challenge after treatment with serum containing VNA and MCP-1 at 5 dpi despite the fact that VNA remained in high titers in the serum. Considering the transient effects of MCP-1 on BBB permeability, an additional dose of MCP-1 at 7 dpi, significantly enhanced the survival rate from $25 \%$ to $78 \%$ (Figure. 1). Thus, it is demonstrated that, VNAs administered in the periphery can clear lethal RABV from the CNS in both immunocompetent and immunocompromised mice as long as the BBB permeability remains enhanced [101]. These studies may provide the foundation for developing VNA therapy for clinical rabies.

\section{Animal model for rabies therapy/treatment}

Mice have been used extensively as an animal model in deciphering rabies pathogenesis and also for the development of vaccines because of their shorter incubation and disease periods and they are available cheaply in large numbers. Although the mouse model is very useful to test the efficacy of RABV vaccines administered prior to challenge, but it is not a suitable model for developing therapy for clinical rabies because of the shorter incubation and disease periods. Dogs are one of the natural hosts for rabies and the incubation period (1-3 months) and disease process (3-7days) in dogs are very similar to those recorded in humans, thus serving the best suited animal model especially for the development of rabies therapy for humans. Our recent studies indicate that the dogs which succumbed to rabies had severe inflammation in the CNS and little or no VNA in the serum or CSF. On the other hand, the dogs which recovered rabies had high level of VNA in the CSF. Therefore it is evident that the production of VNA within the CNS or invasion of VNA from the periphery into the $\mathrm{CNS}$ via compromised $\mathrm{BBB}$ is important for clearing the virus infection from the CNS [102]. Also, studies in mice indicate that the direct administration of VNA along with the enhancement of BBB permeability can clear the RABV from the CNS. Thus, dogs would be an apt model to apply the acquired from mouse/ other studies. Our current understanding of rabies virus clearance is illustrated in Figure. 2 for effective treatment of clinical rabies.

Figure 1. Rabies treatment by peripheral administration of VNA and MCP-1 and its protective efficacy in immunocompetent and B-cell deficient mice treated 5 days after lethal challenge. Normal and B-cell deficient mice were infected i.m with DRV and then treated with serum containing rabies-antibodies (Ab) in conjunction with MCP-1 at $5 \mathrm{dpi}$ or at both 5 and 7 dpi.

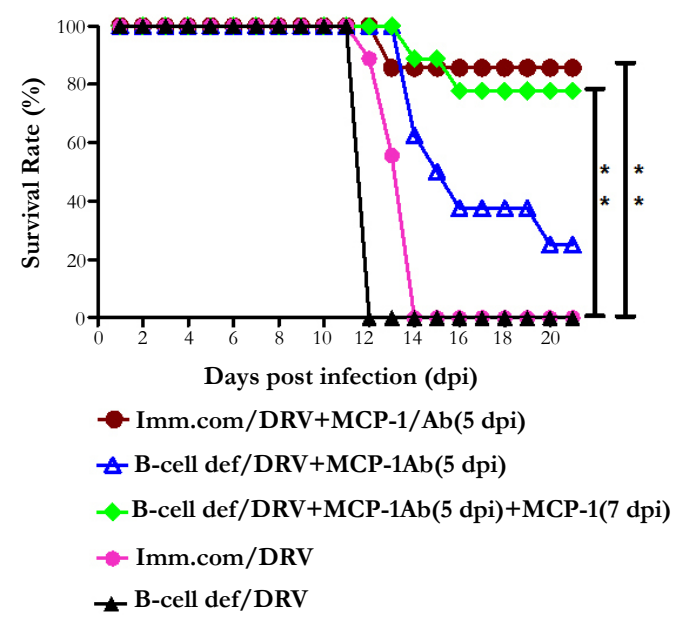


Figure 2. Illustration of RABV clearance from CNS that requires transient opening of the BBB, which allows the entry of immune effectors (VNA) from the periphery.
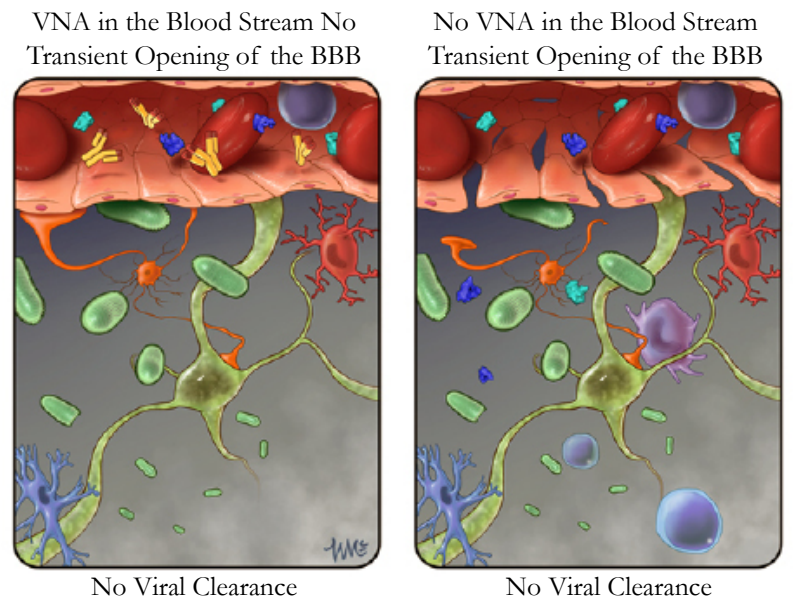

VNA in the Blood Stream Transient Opening of the BBB

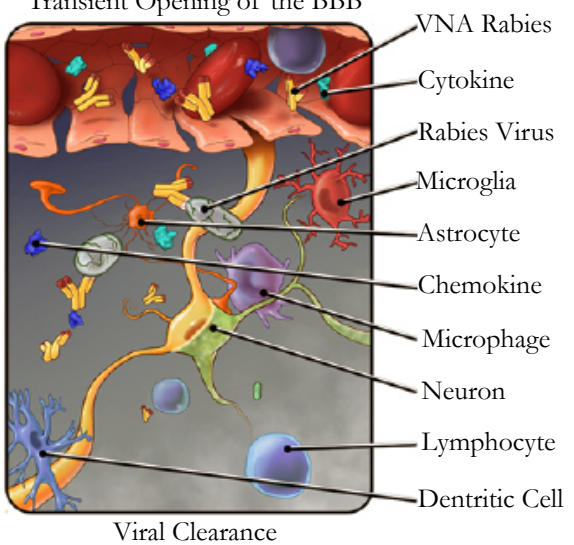

\section{Future research directions for rabies treatment}

Immune clearance of RABV from CNS using bi-specific antibodies

Although drugs have been found to breach the BBB integrity, there are several issues regarding compromising the $\mathrm{BBB}$, one of which is the unwanted immune molecules that enter into the CNS from the periphery may lead to neurological complications. It has been shown in experimental cerebral malaria, vascular leakage is closely associated with brain edema, coma and death [103]. The most acknowledged approach to treat rabies is to avoid meddling with $\mathrm{BBB}$, by using bi-specific antibodies that can cross BBB without altering its function. It has been shown in mice, that a bispecific antibody [one arm specific to TfR (transferrin receptor) and other arm is specific to enzyme $\beta$-secretase] can efficiently cross the $\mathrm{BBB}$ and reduced the accumulation of amyloid- $\beta$ peptide in the CNS [104]. Therefore it is plausible to construct a bispecific antibody, one arm recognizing the TfR, which is highly expressed by the endothelial cells that make up the BBB and other arm recognizing rabies $G$ protein (with neutralizing ability). Thus, such bi-specific antibodies which retain the ability to cross the $\mathrm{BBB}$ and to neutralize RABVs in the CNS would help us to establish an effective therapy for rabies in humans.

\section{Neuroprotective therapy for rabies}

Although, RABV clearance from CNS is the first and crucial step towards rabies treatment, however it is equally important to ameliorate the neuronal injury for complete recovery from rabies. Despite extensive investigation, the mechanism by which RABV infection causes neurological disease and damage is still not completely understood. It is shown that RABV infection causes dysfunction of ions channels, such as reduction in sodium and potassium channels $[105,106]$. Also, there are evidence of impaired release of neurotransmitters such as serotonin, norepinephrine and dopamine at synaptic junctions which could result in functional impairment [3]. Investigation of structural alterations of neuronal processes in rabies infection showed severe destruction and disorganization of neuronal processes in mice infected with pathogenic but not in attenuated rabies virus. Detailed structural analysis using electron microscopy indicates loss of synaptic structures and vesicles, suggesting pathogenic RABV infection causes degeneration of neuronal processes by disrupting cy- toskeletal integrity [107]. All these evidence indicate that rabies infection causes severe damages to neurons. Though, it is unclear whether the rabies induced neuronal damages are reversible but it is critical to ameliorate the neuronal injury, as a part of rabies therapy for complete recovery.

It is self-evident that the adult mammalian brain and spinal cord do not regenerate after injury or damage, but recent discoveries have forced a reconsideration of this accepted principle. As reported by Cajal in 1928 that the adult CNS neurons could regrow if they were provided access to permissive environment of a conditioned sciatic nerve [108]. Aguyao et al., replicated these studies with new methods that confirmed the regenerative capabilities of adult neurons [109]. It is clear from these findings that the failure for CNS neuron to regenerate is not an intrinsic deficit, but rather a characteristic feature of the damaged environment that did not support regeneration. In the past few years the elements promotes neurons regeneration or inhibition have been discovered. Neurotrophins (NT) which includes, nerve growth factor (NGF), brainderived neurotrophic factor (BDNF), NT-3, NT-4/5, and NT-6, are a family of closely related proteins that were first identified as survival factors for sympathetic and sensory neurons and since have been shown to control survival, development and function of neurons in both central and peripheral nervous system [110]. Beside these, they are believed to be at least partially responsible for axon guidance and maintenance of CNS integrity [111-113]. Thus, these studies highlight the importance of NT on neuronal survival and regeneration. It would be interesting to explore the beneficial effect of "neurotrophins" in rabies therapy, by generating a chimeric attenuated RABV expressing BDNF or NGF. Such chimeric attenuated viruses could play dual role on virus clearance from CNS and also could provide a permissive environment for the rejuvenation of neurons. Such studies in animal models aimed at treating rabies using novel approaches would contribute to the establishment of an effective therapy for human rabies.

\section{Conclusion}

The intent of this review is to provide insight into the current understanding of rabies pathogenesis for the purpose of developing and evaluating efficient treatments. Despite significant progress, rabies remains an important global disease. Successful vaccines have been developed for post-exposure prophylaxis. Yet, PEP is ineffective once clinical signs have appeared indicating active vi- 
rus replication in the CNS. Recent studies aimed at improving the efficacy of PEP of rabies or clearance of virus from the CNS indicate that the presence of RABV-specific immunity (VNA) in the CNS and the transient opening of $\mathrm{BBB}$ permeability is an absolute requirement for effective virus clearance from the CNS. In principle, it has been shown in mice that various live-attenuated rRABVs like TriGAS or rRABVs expressing chemokine/ cytokines can induce high levels of VNA in the serum and are also capable of transiently opening BBB, resulting in the clearance of RABV from CNS and prevention of mice from developing rabies. Intravenous administration of VNA and MCP-1 (shown to transiently open up BBB) can clear lethal RABV from the CNS in both immunocompetent and immunocompromised mice, as late as 5 days after lethal challenge. However, for an effective treatment and recovery, it is not only important to clear the virus from CNS but also to ameliorate the neuronal injury induced by the viral infection. Therefore, a combination of therapy including antiviral therapy, immunotherapy and neuroprotective therapy should be an important area of research for the treatment of rabies. Such studies in animal models aimed at treating rabies using novel approaches would contribute to the establishment of an effective therapy for human rabies.

\section{Acknowledgement}

This study was supported partially by Public Health Service grants AI-051560 and AI-093369 from the National Institute of Allergy and Infectious Diseases.

\section{References}

[1]. Albertini AA, Ruigrok RW, Blondel D (2011). Rabies virus transcription and replication. Adv Virus Res 79: 1-22

[2]. Jackson AC, Warrell MJ, Rupprecht CE, Ertl HCJ, Dietzschold B, et al (2003). Management of rabies in humans. Clinical Infectious Diseases 36: 60-63.

[3]. Fu ZF, Jackson AC (2005). Neuronal dysfunction and death in rabies virus infection. J Neurovirol 11: 101-106.

[4]. WHO (2005). WHO Expert Consultation on rabies. World Health Organ Tech Rep Ser 931: 1-88, back cover.

[5]. Wilde H, Wacharapluesadee S, Hemachudha T (2012). Currently approved post-exposure rabies prophylaxis regimens. Travel Med Infect Dis 10: 162163.

[6]. Wilde H. (2012) Rabies Postexposure Vaccination: Are Antibody Responses Adequate? Clinical Infectious Diseases 55: 206-208.

[7]. Wu XF, Gong XM, Foley HD, Schnell MJ, Fu ZF (2002). Both viral transcription and replication are reduced when the rabies virus nucleoprotein is not phosphorylated. Journal of Virology 76: 4153-4161.

[8]. CDC (2011). The Rabies Virus. http://www.cdc.gov/rabies/transmission/ virus.html. Accessed

[9]. Emerson SU, Schubert M (1987). Location of the Binding Domains for the Rna Polymerase-L and the Ribonucleocapsid Template within Different Halves of the Ns Phosphoprotein of Vesicular Stomatitis-Virus. Proceedings of the National Academy of Sciences of the United States of America 84: 5655-5659.

[10]. Gaudin Y (2000). Rabies virus-induced membrane fusion pathway. Journal of Cell Biology 150: 601-611.

[11]. Arnheiter H, Davis NL, Wertz G, Schubert M, Lazzarini RA. (1985). Role of the Nucleocapsid Protein in Regulating Vesicular Stomatitis-Virus RnaSynthesis. Cell 41: 259-267.

[12]. Lahaye X, Vidy A, Pomier C, Obiang L, Harper F, et al (2009). Functional characterization of Negri bodies (NBs) in rabies virus-infected cells: Evidence that NBs are sites of viral transcription and replication. J Virol 83: 7948-7958.

[13]. Yousaf MZ, Qasim M, Zia S, Khan M, Ashfaq UA, Khan S. (2012). Rabies molecular virology, diagnosis, prevention and treatment. Virol J 9: 50.

[14]. WHO (2011). Global Vaccine Research Forum. http://www.who.int/vaccine_research/about/gvrf/en/index.html.

[15]. Lackay SN, Kuang Y, Fu ZF (2008). Rabies in small animals. Vet Clin North Am Small Anim Pract 38: 851-861, ix.
[16]. Finnegan CJ, Brookes SM, Johnson N, Smith J, Mansfield KL, et al (2002). Rabies in North America and Europe. J R Soc Med 95: 9-13.

[17]. Irsara A, Ruatti A, Gagliardi G, Orfei Z, Bellani L, Mantovani A. (1982). [Control of wildlife rabies in North-Eastern Italy]. Comp Immunol Microbiol Infect Dis 5: 327-335.

[18]. SilleroZubiri C, King AA, Macdonald DW (1996). Rabies and mortality in Ethiopian wolves (Canis simensis). Journal of Wildlife Diseases 32: 80-86.

[19]. King AA, Meredith CD, Thomson GR (1993). Canid and Viverrid Rabies Viruses in South-Africa. Onderstepoort Journal of Veterinary Research 60: 295-299.

[20]. Morimoto K, Patel M, Corisdeo S, Hooper DC, Fu ZF et al (1996). Characterization of a unique variant of bat rabies virus responsible for newly emerging human cases in North America. Proceedings of the National Academy of Sciences of the United States of America 93: 5653-5658.

[21]. Constantine DG (1979). Updated List of Rabies-Infected Bats in NorthAmerica. Journal of Wildlife Diseases 15: 347-349.

[22]. Sulkin SE (1965). Chiropteran (bat) rabies in North America. Hawaii Med J 25: 149-153.

[23]. Krebs JW, Rupprecht CE, Childs JE (2000). Rabies surveillance in the United States during 1999. Journal of the American Veterinary Medical Association 217: 1799-1811.

[24]. Who (2005). Who Expert Consultation on Rabies - Introduction. Who Expert Consultation on Rabies 931: 1-88.

[25]. Dietzschold B, Kao M, Zheng YM, Chen ZY, Maul G, et al (1992). Delineation of Putative Mechanisms Involved in Antibody-Mediated Clearance of Rabies Virus from the Central-Nervous-System. Proceedings of the National Academy of Sciences of the United States of America 89: 7252-7256.

[26]. Schumacher CL, Dietzschold B, Ertl HCJ, Niu HS, Rupprecht CE, Koprowski H. (1989). Use of Mouse Anti-Rabies Monoclonal-Antibodies in Postexposure Treatment of Rabies. Journal of Clinical Investigation 84: 971 975.

[27]. Dreesen DW (1997). A global review of rabies vaccines for human use. Vaccine 15: S2-S6

[28]. Desai SM, Sehgal PB, Nanavati AN, Shirodka.Mv (1973). Rabies-Induced Serum Factor Inhibiting Rous-Sarcoma Virus in Chicks. Journal of General Virology 19: 285-293.

[29]. Dureux B, Canton P, Gerard A, Strady A, Deville J, et al (1986). Rabies Vaccine for Human Use, Cultivated on Vero Cells. Lancet 2: 98-98.

[30]. Seghal S, Bhattacharya D, Bhardwaj M (1997). Five-year longitudinal study of efficacy and safety of purified Vero cell rabies vaccine for post-exposure prophylaxis of rabies in Indian population. J Commun Dis 29: 23-28.

[31]. Wilde H (2007). Failures of post-exposure rabies prophylaxis. Vaccine 25: 7605-7609.

[32]. Wu X, Smith TG, Rupprecht CE (2011). From brain passage to cell adaptation: the road of human rabies vaccine development. Expert Rev Vaccines 10: 1597-1608.

[33]. Wandeler AI, Capt S, Kappeler A, Hauser R (1988). Oral immunization of wildlife against rabies: concept and first field experiments. Rev Infect Dis 10 Suppl 4: S649-653.

[34]. Flamand A, Coulon P, Lafay F, Tuffereau C (1993). Avirulent mutants of rabies virus and their use as live vaccine. Trends Microbiol 1:317-320.

[35]. Steck F, Wandeler A, Bichsel P, Capt S, Hafliger U, Schneider L (1982). Oral immunization of foxes against rabies. Laboratory and field studies. Comp Immunol Microbiol Infect Dis 5: 165-171.

[36]. Kieny MP, Lathe R, Drillien R, Spehner D, Skory S, (1984). Expression of rabies virus glycoprotein from a recombinant vaccinia virus. Nature 312 : 163-166.

[37]. Rupprecht CE, Blass L, Smith K, Orciari LA, Niezgoda M, et al (2001). Human infection due to recombinant vaccinia-rabies glycoprotein virus. $\mathrm{N}$ Engl J Med 345: 582-586.

[38]. Schneider LG, Cox JH, Muller WW, Hohnsbeen KP (1988). Current Ora Rabies Vaccination in Europe - an Interim Balance. Reviews of Infectious Diseases 10: S654-S659.

[39]. Schumacher CL, Coulon P, Lafay F, Benejean J, Aubert MFA, Barrat J, et al (1993). Sag-2 Oral Rabies Vaccine. Onderstepoort Journal of Veterinary Research 60: 459-462.

[40]. MacInnes CD, Smith SM, Tinline RR, Ayers NR, Bachmann P, et al (2001). Elimination of rabies from red foxes in eastern Ontario. J Wildl Dis 37: 119-132.

[41]. Hanlon CA, Niezgoda M, Morrill P, Rupprecht CE (2002). Oral efficacy of an attenuated rabies virus vaccine in skunks and raccoons. Journal of Wildlife Diseases 38: 420-427.

[42]. Franka R, Wu X, Jackson FR, Velasco-Villa A, Palmer DP, Henderson H, (2009). Rabies virus pathogenesis in relationship to intervention with inactivated and attenuated rabies vaccines. Vaccine 27: 7149-7155.

[43]. Benmansour A, Leblois H, Coulon P, Tuffereau C, Gaudin Y, et al (1991). Antigenicity of rabies virus glycoprotein. J Virol 65: 4198-4203.

[44]. Ito N, Takayama M, Yamada K, Sugiyama M, Minamoto N (2001). Rescue 
of rabies virus from cloned cDNA and identification of the pathogenicityrelated gene: glycoprotein gene is associated with virulence for adult mice. J Virol 75: 9121-9128.

[45]. Lentz TL, Burrage TG, Smith AL, Crick J, Tignor GH (1982). Is the Acetylcholine-Receptor a Rabies Virus Receptor. Science 215: 182-184.

[46]. Thoulouze MI, Lafage M, Schachner M, Hartmann U, Cremer H, Lafon M (1998). The neural cell adhesion molecule is a receptor for rabies virus. J Virol 72: 7181-7190.

[47]. Morimoto K, Foley HD, McGettigan JP, Schnell MJ, Dietzschold B (2000). Reinvestigation of the role of the rabies virus glycoprotein in viral pathogenesis using a reverse genetics approach. Journal of Neurovirology 6: 373-381.

[48]. Shankar V, Dietzschold B, Koprowski H (1991). Direct entry of rabies virus into the central nervous system without prior local replication. J Virol 65: 2736-2738.

[49]. Tsiang H, Ceccaldi PE, Lycke E (1991). Rabies virus infection and transport in human sensory dorsal root ganglia neurons. J Gen Virol 72 ( Pt 5): 1191-1194.

[50]. Finke S, Conzelmann KK (2005). Replication strategies of rabies virus. Virus Research 111:120-131.

[51]. Wang ZW, Sarmento L, Wang YH, Li XQ, Dhingra V, Tseggai T (2005). Attenuated rabies virus activates, while pathogenic rabies virus evades, the host innate immune responses in the central nervous system. Journal of Virology 79: 12554-12565.

[52]. Johnson N, Mansfield KL, Mckimmie CS, Fazakerley JK, Fooks AR (2005). Host innate immune responses to rabies virus infection of the central nervous system. Immunology 116: 90-90.

[53]. Kuang Y, Lackay SN, Zhao L, Fu ZF (2009). Role of chemokines in the enhancement of BBB permeability and inflammatory infiltration after rabies virus infection. Virus Research 144: 18-26.

[54]. Sarmento L, Tseggai T, Dhingra V, Fu ZF (2006). Rabies virus-induced apoptosis involves caspase-dependent and caspase-independent pathways. Virus Research 121: 144-151.

[55]. Zhang GQ, Wang HL, Mahmood F, Fu ZF (2013). Rabies virus glycoprotein is an important determinant for the induction of innate immune responses and the pathogenic mechanisms. Veterinary Microbiology 162: 601-613.

[56]. Fabis MJ, Phares TW, Kean RB, Koprowski H, Hooper DC (2008). Bloodbrain barrier changes and cell invasion differ between therapeutic immune clearance of neurotrophic virus and CNS autoimmunity. Proceedings of the National Academy of Sciences of the United States of America 105: 1551115516.

[57]. Roy A, Hooper DC (2007). Lethal silver-haired bat rabies virus infection can be prevented by opening the blood-brain barrier. Journal of Virology 81: 7993-7998.

[58]. Roy A, Phares TW, Koprowski H, Hooper DC (2007). Failure to open the blood-brain barrier and deliver immune effectors to central nervous system tissues leads to the lethal outcome of silver-haired bat rabies virus infection. Journal of Virology 81: 1110-1118.

[59]. Murphy FA (1977). Rabies pathogenesis. Arch Virol 54: 279-297.

[60]. Hooper DC, Roy A, Kean RB, Phares TW, Barkhouse DA. 2011. Therapeutic immune clearance of rabies virus from the CNS. Future Virology 6:387-397.

[61]. Fekadu M, Baer GM. 1980. Recovery from clinical rabies of 2 dogs inoculated with a rabies virus strain from Ethiopia. Am J Vet Res 41:1632-1634.

[62]. Miller A, Morse HC, 3rd, Winkelstein J, Nathanson N (1978). The role of antibody in recovery from experimental rabies. I. Effect of depletion of B and T cells. J Immunol 121: 321-326.

[63]. Alvarez L, Fajardo R, Lopez E, Pedroza R, Hemachudha T, et al (1994). Partial recovery from rabies in a nine-year-old boy. Pediatr Infect Dis J 13:11541155

[64]. Centers for Disease C, Prevention. (2004). Recovery of a patient from clinical rabies--Wisconsin, (2004). MMWR Morb Mortal Wkly Rep 53: 11711173 .

[65]. Centers for Disease C, Prevention (2012). Recovery of a patient from clinical rabies--California, (2011). MMWR Morb Mortal Wkly Rep 61: 61-65.

[66]. Willoughby RE, Jr., Tieves KS, Hoffman GM, Ghanayem NS, Amlie-Lefond CM, Schwabe MJ, et al (2005). Survival after treatment of rabies with induction of coma. N Engl J Med 352: 2508-2514.

[67]. Hattwick MA, Weis TT, Stechschulte CJ, Baer GM, Gregg MB (1972). Recovery from rabies. A case report. Ann Intern Med 76: 931-942.

[68]. Porras C, Barboza JJ, Fuenzalida E, Adaros HL, Oviedo AM, Furst J (1976). Recovery from rabies in man. Ann Intern Med 85: 44-48

[69]. Madhusudana SN, Nagaraj D, Uday M, Ratnavalli E, Kumar MV (2002). Partial recovery from rabies in a six-year-old girl. Int J Infect Dis 6: 85-86.

[70]. Winkler WG, Fashinell TR, Leffingwell L, Howard P, Conomy P (1973). Airborne rabies transmission in a laboratory worker. JAMA 226: 1219-1221.

[71]. Hu WT, Willoughby RE, Dhonau H, Mack KJ (2007). Long-term followup after treatment of rabies by induction of coma. New England Journal of
Medicine 357: 945-946.

[72]. Bahri F, Letaief A, Ernez M, Elouni J, Chekir T, Ben Ammou S, Jemni L (1996). [Neurological complications in adults following rabies vaccine prepared from animal brains]. Presse Med 25: 491-493.

[73]. Jackson AC (2011). Therapy of human rabies. Adv Virus Res 79: 365-375.

[74]. Jackson AC (2005). Transmission of rabies from an organ donor. N Engl J Med 352: 2551-2552; author reply 2552.

[75]. Jackson AC (2013). Current and future approaches to the therapy of human rabies. Antiviral Research 99: 61-67.

[76]. Jackson AC, Scott CA, Owen J, Weli SC, Rossiter JP (2008). Human rabies therapy: lessons learned from experimental studies in mouse models. Dev Biol (Basel) 131: 377-385

[77]. Hemachudha T, Sunsaneewitayakul B, Desudchit T, Suankratay C, Sittipun C, (2006). Failure of therapeutic coma and ketamine for therapy of human rabies. Journal of Neurovirology 12: 407-409.

[78]. Miller AE, Morse HC, Nathanson N (1977). Studies on Immunological Clearance of Experimental Rabies in Mice. Journal of Neuropathology and Experimental Neurology 36: 617-617.

[79]. Phares TW, Kean RB, Mikheeva T, Hooper DC (2006). Regional differences in blood-brain barrier permeability changes and inflammation in the apathogenic clearance of virus from the central nervous system. J Immunol 176: 7666-7675

[80]. Ballabh P, Braun A, Nedergaard M (2004). The blood-brain barrier: an overview: structure, regulation, and clinical implications. Neurobiol Dis 16 : $1-13$.

[81]. Roy A, Hooper DC (2008). Immune evasion by rabies viruses through the maintenance of blood-brain barrier integrity. J Neurovirol 14: 401-411.

[82]. Begley DJ (2004). Delivery of therapeutic agents to the central nervous system: the problems and the possibilities. Pharmacol Ther 104: 29-45.

[83]. Weissert R, Herrmann MM, Barth S, Schumann KM, Viskorf A (2004). Functional genomics in experimental autoimmune encephalomyelitis and multiple sclerosis. Journal of Neuroimmunology 154: 20-20.

[84]. Bennett J, Basivireddy J, Kollar A, Biron KE, Reickmann P, Jefferies WA, McQuaid S (2010). Blood-brain barrier disruption and enhanced vascular permeability in the multiple sclerosis model EAE. Journal of Neuroimmunology 229: 180-191.

[85]. Nelson DA, Berry RG (1993). Fatal rabies associated with extensive demyelination. Arch Neurol 50: 317-323

[86]. Hooper DC, Morimoto K, Bette M, Weihe E, Koprowski H, Dietzschold B (1998). Collaboration of antibody and inflammation in clearance of rabies virus from the central nervous system. Journal of Virology 72: 3711-3719.

[87]. Schnell MJ, Tan GS, Dietzschold B (2005). The application of reverse genetics technology in the study of rabies virus (RV) pathogenesis and for the development of novel RV vaccines. J Neurovirol 11: 76-81.

[88]. Faber M, Faber ML, Papaneri A, Bette M, Weihe E, et al (2005). A single amino acid change in rabies virus glycoprotein increases virus spread and enhances virus pathogenicity. J Virol 79: 14141-14148.

[89]. Dietzschold ML, Faber M, Mattis JA, Pak KY, Schnell MJ, Dietzschold B (2004). In vitro growth and stability of recombinant rabies viruses designed for vaccination of wildlife. Vaccine 23: 518-524.

[90]. Faber M, Pulmanausahakul R, Hodawadekar SS, Spitsin S, McGettigan JP, et al (2002). Overexpression of the rabies virus glycoprotein results in enhancement of apoptosis and antiviral immune response. J Virol 76: 3374 3381.

[91]. Faber M, Faber ML, Li J, Preuss MA, Schnell MJ, Dietzschold B (2007), Dominance of a nonpathogenic glycoprotein gene over a pathogenic glycoprotein gene in rabies virus. J Virol 81: 7041-7047.

[92]. Faber M, Li J, Kean RB, Hooper DC, Alugupalli KR, Dietzschold B (2009). Effective preexposure and postexposure prophylaxis of rabies with a highly attenuated recombinant rabies virus. Proc Natl Acad Sci U S A 106: 1130011305.

[93]. Li J, Ertel A, Portocarrero C, Barkhouse DA, Dietzschold B, Hooper DC, Faber M. (2012). Postexposure treatment with the live-attenuated rabies virus (RV) vaccine TriGAS triggers the clearance of wild-type RV from the Central Nervous System (CNS) through the rapid induction of genes relevant to adaptive immunity in CNS tissues. J Virol 86: 3200-3210.

[94]. Zhou M, Zhang G, Ren G, Gnanadurai CW, Li Z, et al (2013). Recombinant rabies viruses expressing GM-CSF or flagellin are effective vaccines for both intramuscular and oral immunizations. PLoS One 8: e63384.

[95]. Wen Y, Wang H, Wu H, Yang F, Tripp RA, Hogan RJ, et al (2011). Rabies virus expressing dendritic cell-activating molecules enhances the innate and adaptive immune response to vaccination. J Virol 85: 1634-1644.

[96]. Wang HL, Zhang GQ, Wen YJ, Yang ST, Xia XZ, Fu ZF (2011). Intracerebral Administration of Recombinant Rabies Virus Expressing GM-CSF Prevents the Development of Rabies after Infection with Street Virus. Plos One 6.

[97]. Leclercq SY, dos Santos RMM, Macedo LB, Campos PC, Ferreira TC, et al (2011). Evaluation of water-in-oil-in-water multiple emulsion and mi- 
croemulsion as potential adjuvants for immunization with rabies antigen. European Journal of Pharmaceutical Sciences 43: 378-385.

[98]. Niu X, Wang H, Fu ZF (2011). Role of chemokines in rabies pathogenesis and protection. Adv Virus Res 79: 73-89.

[99]. Baer GM, Shaddock JH, Williams LW (1975). Prolonging morbidity in rabid dogs by intrathecal injection of attenuated rabies vaccine. Infect Immun 12: 98-103.

[100]. Kesdangsakonwut S, Sunden Y, Aoshima K, Iwaki Y, Okumura M, Sawa H, Umemura T (2014). Survival of rabid rabbits after intrathecal immunization. Neuropathology 34: 277-283.

[101]. Huang CT, Li ZG, Huang Y, Zhang GQ, Zhou M, (2014). Enhancement of blood-brain barrier permeability is required for intravenously administered virus neutralizing antibodies to clear an established rabies virus infection from the brain and prevent the development of rabies in mice. Antiviral Research 110: 132-141.

[102]. Gnanadurai CW, Zhou M, He WQ, Leyson CM, Huang CT, (2013). Presence of Virus Neutralizing Antibodies in Cerebral Spinal Fluid Correlates with Non-Lethal Rabies in Dogs. Plos Neglected Tropical Diseases 7.

[103]. Nacer A, Movila A, Baer K, Mikolajczak SA, Kappe SH, Frevert U (2012). Neuroimmunological blood brain barrier opening in experimental cerebral malaria. PLoS Pathog 8: e1002982.

[104]. Yu YJ, Zhang Y, Kenrick M, Hoyte K, Luk W, et al (2011). Boosting brain uptake of a therapeutic antibody by reducing its affinity for a transcytosis target. Sci Transl Med 3: 84ra44.

[105]. Iwata M, Komori S, Unno T, Minamoto N, Ohashi H (1999). Modification of membrane currents in mouse neuroblastoma cells following infection with rabies virus. Br J Pharmacol 126: 1691-1698.

[106]. Iwata M, Unno T, Minamoto N, Ohashi H, Komori S. (2000). Rabies virus infection prevents the modulation by alpha(2)-adrenoceptors, but not muscarinic receptors, of $\mathrm{Ca}(2+)$ channels in NG108-15 cells. Eur J Pharmacol 404: 79-88.
[107]. Li XQ, Sarmento L, Fu ZF (2005). Degeneration of neuronal processes after infection with pathogenic, but not attenuated, rabies viruses. J Virol 79: 10063-10068.

[108]. Lobato RD (2008). Historical vignette of Cajal's work "Degeneration and regeneration of the nervous system" with a reflection of the author. Neurocirugia (Astur) 19: 456-468.

[109]. Richardson PM, Mcguinness UM, Aguayo AJ (1980). Axons from Cns Neurons Regenerate into Pns Grafts. Nature 284: 264-265.

[110]. Skaper SD (2012). The neurotrophin family of neurotrophic factors: an overview. Methods Mol Biol 846: 1-12.

[111]. Davies AM (2000). Neurotrophins: More to NGF than just survival. Current Biology 10: R374-R376.

[112]. Davies AM. (2000). Neurotrophins: Neurotrophic modulation of neurite growth. Current Biology 10: R198-R200.

[113]. Gurgo RD, Bedi KS, Nurcombe V (2002). Current concepts in central nervous system regeneration. Journal of Clinical Neuroscience 9: 613-617.

[114]. Morimoto K, Hooper DC, Spitsin S, Koprowski H, Dietzschold B (1999). Pathogenicity of different rabies virus variants inversely correlates with apoptosis and rabies virus glycoprotein expression in infected primary neuron cultures. J Virol 73: 510-518.

[115]. Yan X, Prosniak M, Curtis MT, Weiss ML, Faber M,et al (2001). Silver-haired bat rabies virus variant does not induce apoptosis in the brain of experimentally infected mice. J Neurovirol 7: 518-527.

[116]. Shoji Y, Inoue S, Nakamichi K, Kurane I, Sakai T, Morimoto K (2004). Generation and characterization of $\mathrm{P}$ gene-deficient rabies virus. Virology 318: 295-305.

[117]. Megret F, Prehaud C, Lafage M, Batejat C, Escriou N, et al (2005). Immunopotentiation of the antibody response against influenza HA with apoptotic bodies generated by rabies virus G-ERA protein-driven apoptosis. Vaccine 23: 5342-5350. 